\title{
LABORATORY EVALUATION OF A SELF-ADHERING FLOWABLE COMPOSITE RESIN AS A PIT AND FISSURE SEALANT
}

\author{
Nour M. Owida ${ }^{1}$ BDS, Nadia A. Wahba ${ }^{2} M S c, P h D$, Dalia M. Talaat ${ }^{3} M S c, P h D$, \\ Bassem F. Elmallakh ${ }^{4} M S c, P h D$
}

\begin{abstract}
INTRODUCTION: The success of pit and fissure sealant is highly dependent on obtaining and maintaining an intimate adaptation to the tooth surface. Self-adherable flowable composite (Vertise Flow) represents a new generation of dental materials that combines the properties of flowable composites and self-adhesives.

OBJECTIVES: The aim of this study was to evaluate the Vertise Flow (VF) in term of shear bond strength and sealing ability to enamel of pit and fissure in comparison to conventional sealant with self-adhesive (Clinpro sealant/ Adper Prompt L pop)

MATERIAL AND METHODS: Sixty extracted sound premolars were selected. These were randomly divided into two groups according to the material used. Group I for Veritse Flow and Group II for Clinpro Sealant. Each group was further divided equally into two sub groups $(n=15)$. GroupI was divided into Ia and Ib to test shear bond strength and microleakage respectively. Group II was divided into IIa and IIb to test shear bond strength and microleakage respectively.

Shear bond strength test: Group Ia buccal surface was treated with phosphoric acid and VF. Group IIa was treated with Clinpro sealant and Adper Prompt L Pop. Shear bond strength was measured using universal testing machine. Mode of failure of each specimen was determined using stereomicroscope. Microleakage test: Group Ib, teeth pit and fissures were acid etched and sealed with VF. Group IIb, Adper Prompt L Pop was applied and teeth were sealed with Clinpro sealant.

Teeth were thermocycled, stained, sectioned and examined under stereomicroscope. Data were collected, tabulated and statistically analyzed using Mann-Whitney U test $(\mathrm{p}<0.05)$.

RESULTS: Group I (VF) showed significantly higher shear bond strength and lower microleakage score than Group II (Clinpro sealant/PLP) $(\mathrm{p}<0.05)$. adhesive mode of failure was the predominant mode in group IIa with statistical significance.

CONCLUSIONS: Vertise Flow shows encouraging results to be used as a pit and fissure sealant.
\end{abstract}

KEYWORDS: sealant, self-adherable composite, Vertise Flow, shear bond strength, microleakage.

1- Bachelor of Dentistry, Faculty of Dentistry, Alexandria University, Alexandria, Egypt.

2- Professor of Pediatric Dentistry, Faculty of Dentistry, Alexandria University, Alexandria, Egypt

3- Associate Professor of Pediatric Dentistry, Faculty of Dentistry, Alexandria University, Alexandria, Egypt.

4- Professor of Dental Biomaterials department, Faculty of Dentistry, Alexandria University, Alexandria, Egypt.

Corresponding author:

E-mail: dr.nourowida@gmail.com

\section{INTRODUCTION}

Current dentistry privileges minimal intervention methods. It has become focused on reducing Patients risk for caries, stimulating preventive measures and preserving tooth structure. Among these methods, pit and fissure sealing is a widely accepted approach for preventing occlusal caries $(1,2)$.

The term pit and fissure sealant is used to describe a material that is introduced into the occlusal pits and fissures of caries-susceptible teeth, thus forming a micromechanically-bonded, protective layer cutting access of caries-producing bacteria from their source of nutrients (3). Siegel (4) stated that "sealants are an important dental caries prevention technology, ideally used in combination with patient education, effective personal oral hygiene, fluorides and regular dental visits.” The preventive benefit of pit and fissure sealing relies directly upon the ability of the sealant to thoroughly fill pits and fissures and/or morphological defects and remain completely intact and bonded to enamel surface. The positive features of pit and fissure sealants are to some extent determined by their physical properties and in many ways, are related to their rate of retention in the oral cavity (5).

The marginal sealing ability of sealing materials is not any less important. It is extremely important for successful treatment as lack of sealing allows for the occurrence of marginal leakage, i.e., passage of bacteria, fluids, molecules and ions through the tooth-material interface, this can prompt caries lesion progression underneath the restoration (6). Incorporation of a layer of hydrophilic bonding agent between the sealant and enamel is a technique suggested and recommended by Hitt and Feigal (7) for increasing the fissure sealant bond strength. Beauchamp et al (8) and Tavassoli et al (9) demonstrated that this technique, in both moist and dry conditions, increases the bond strength and decreases the microleakage. In addition, the latter also reported that self-etch adhesives (SEA) can be used with sealant to improve its retention. In contrast Mascarenhas et al (10) reported no enhancement for sealant retention with adding bonding agent underneath the sealant. Most commonly used systems for sealing are lightly filled or unfilled resin based materials in combination with phosphoric acid for etching which renders the enamel surface porous. The low viscosity of the sealants allows penetration of the material into pits and fissures, forming a resin-impregnated layer of enamel $(11,12)$.

Composite resins with a reduced filler load and a lower modulus of elasticity marketed as "flowable" composites have been used in pit and fissure sealing (13). In addition to the development of a lower stress, flowable composite 
resins offer the advantage of favorable handling properties. Their viscosity is such that material placement is eased and its adaptation is improved (14). As flowable composite resins do not have adhesive properties per se, the combined use of a dental bonding system is necessary. Al-Saleh (15) reported that flowable composite showed better performance as a pit and fissure sealant than conventional sealant. The author stated that adding bonding agent layer under flowable composite improved its retention. Recently, innovative resin-based material, combining the properties of self-adhesion and flowability were developed (16).

The first self-adherable flowable composite is Vertise Flow (Kerr, Orange, CA, USA). This material is claimed to eliminate the need for a separate bonding application step, thus simplifying the direct restorative procedure. For this reason, Vertise Flow (VF) may be considered to start the 8th generation of dental adhesive systems or to represent a cross-link between all-in-one adhesive systems and flowable composite resins (14). The bonding mechanism of Vertise Flow relies on its functional monomer Glycerol phosphate dimethacrylate (GPDM). It bonds to the calcium ions of enamel and dentine; thus, it offers micromechanical and chemical bond (17). Vertise Flow has been indicated for the restoration of small Class I cavities, Class V cavities, non-carious cervical lesions, for lining in Class I and Class II restorations, and for pit and fissure sealing (12). In order to improve the adhesion of VF to unground enamel, enamel etching has been advised by the manufacturer (14).

As there are few published data about the performance of Vertise Flow as a pit and fissure sealant, this study aimed to evaluate Vertise Flow in its bond strength to enamel and sealing ability of pits and fissures. The proposed study hypothesis was that a new self-adhering flowable resin composite and a marketed sealant used in combination with a SEA achieve similar shear bond strength to enamel and comparable seal to pit and fissure walls.

\section{MATERIALS AND METHODS}

This experimental in vitro study was performed at the Pediatric Dentistry Department and Biomaterials Department, Faculty of Dentistry, Alexandria University. Sixty non-carious premolars with deep and retentive pits and fissures extracted for orthodontic reason were collected after the approval of the ethical committee. They were cleaned from debris and blood with aqueous slurry of pumice and then stored in physiologic saline at room temperature until ready for use. The teeth were randomly divided into two groups according to the material used. Group I: for Veritse Flow and Group II for Clinpro Sealant. Each group was further divided equally into two sub groups $(n=15)$. Group I was divided into Ia and Ib to test shear bond strength and microleakage respectively. Group II was divided into IIa and IIb to test shear bond strength and microleakage respectively. The number of teeth to be included in the study was estimated based on assumption of $5 \%$ type I error and $20 \%$ type II error. The estimated sample size needed per subgroup was 14 teeth calculated using Medcalc.

\section{a. Shear bond strength test:}

Group Ia: Teeth were acid etched and treated with Vertise Flow (Kerr, Orange, CA, USA).

Group IIa: Teeth were treated with Adper prompt L Pop (PLP) and Clinpro sealant (3M ESPE, St. Paul, MN, USA).
The crown of each tooth was separated from the root $2 \mathrm{~mm}$ below the cementum-enamel junction with a watercooled, low-speed diamond saw. Each specimen was mounted in self-curing acrylic resin with its sound buccal surface displayed perpendicular to the long axis of the block. The buccal surfaces were ground flat using 800 and 1000 grit wet silicon carbide finishing paper under watercooling. Both sealants were applied to the flattened buccal enamel surface in increments and according to the manufacturers' instructions using a cylindrical plastic tube (4mm in diameter and $3 \mathrm{~mm}$ in height) perpendicularly centralized over the treated enamel surface and stabilized by sticky wax (18).

In group Ia, the enamel surface was etched with $37.5 \%$ phosphoric acid (PA) for 15 seconds, rinsed for 10 secs and air-dried for $5 \mathrm{sec}$. VF was applied in the plastic mold in increments. Each increment was brushed for 15-20s with the proprietary microbrush and light-cured with LED light cure system (Ivoclar Vivadent, Germany) so as to create a 2-mm thick build up (12). In group IIa, a layer of the selfetch adhesive PLP was applied to the plastic mold and light cured for 15s, then, Clinpro sealant was applied and condensed to the mold and light cured for 20s. The plastic mold was then removed carefully and the specimens in both groups were left undisturbed for 24 hours in an incubator at $100 \%$ humidity at $37^{\circ} \mathrm{C}$ prior to shear bond strength testing (12).

Each specimen was mounted in a special attachment in a Universal Testing Machine (Instron, Comten Industries, USA). The force was applied with a metallic loading blade placed as close as possible and parallel to the junction of the tested material and the enamel surface with cross head speed $1 \mathrm{~mm} / \mathrm{min}$. Shear bond strength was then measured by determining the force required to dislodge the sealant from the enamel surface. Bond strength was calculated in Megapascals (MPa) via dividing the load at failure (Newtons) by the adhesive surface area of the attachment (mm2).

The fracture assemblies for each specimen were evaluated by a single operator under a stereomicroscope (Olympus Co. Germany) at 40x magnification to determine the location and type of failure and classified as: Cohesive Failure (failure occurred within the substrate enamel or sealing material), Adhesive Failure (between sealing material and enamel) and Mixed Failure (adhesive and cohesive failures occurred simultaneously) (19).

\section{b. Microleakage Test}

Each tooth was mounted in self-curing acrylic resin using cuboidal copper molds with the occlusal surface facing upwards and perpendicular to the long axis of the block.

In group Ib: occlusal pits and fissures for each specimen was etched with $37.5 \%$ PA for 15 secs, and then rinsed for 10 secs and air-dried for 5 sec. VF was then applied and brushed for15-20 sec with the proprietary micro-brush and light-cured.

In group IIb: PLP was applied, agitated for $15 \mathrm{sec}$ and air dried. Clinpro Sealant was then applied and light-cured according to the manufacturers' instructions.

All sealed teeth were stored in $0.9 \%$ normal saline until thermocycling. Teeth were thermocycled in a water bath between $5^{\circ} \mathrm{C}$ and $55^{\circ} \mathrm{C}$ for 500 cycles with a dwell time (time taken by each specimen in the bath) of 30 seconds (20). After thermocycling, teeth surfaces were coated with two layers of nail varnish except for $1 \mathrm{~mm}$ around the sealant 
margins. Teeth were then immersed in a $1 \%$ solution of methylene blue for 24 hours to allow dye penetration into possible gaps between enamel and sealant (21). Finally, teeth were dried and sectioned with a water-cooled diamond saw in a buccolingual direction through the sealant resulting in two sections for each specimen.

Each section was examined twice by a single examiner under stereomicroscope at $60 \mathrm{X}$ magnification. The extent of dye penetration was assessed for all sections according to a method described by Overbo and Raadal. "(22) as: 0 (No dye penetration),1 (Dye penetration restricted to the outer half of the sealant), 2 (Dye penetration extended to the inner half sealant) and 3 (Dye penetration into underlying fissure). The section, which was most infiltrated, was considered and recorded as the score for the specimen. The intraexaminer reliability assessed using Kappa was 0.860 and weighted Kappa was 0.928.

\section{STATISTICAL ANALYSIS}

Data were collected and entered to the computer using SPSS (Statistical Package for Social Science) program for statistical analysis (ver 21) (22). Data were entered as numerical or categorical, as appropriate. Data were described using minimum, maximum, mean, standard deviation, median and inter-quartile range. Kolmogorov-Smirnov test revealed significance in the distribution of variables thus, MannWhitney U non-parametric test was carried out. Chi square test and Post-hoc analysis were used to compare mode of failure between the two groups. In the present study, an alpha level was set to $5 \%$ with a significance level of $95 \%$, and a beta error accepted up to $20 \%$ with a power of study of $80 \%$.

\section{RESULTS}

\section{I.Shear bond strength test}

Mann-Whitney U test showed statistical significant difference between the two groups. In favor of Group Ia (VF) with ( $\mathrm{p}=$ 0.000). (Table I) (Fig. 1) Regarding the mode of failure, mixed mode of failure was the predominant mode in group Ia (66.7\%) with no significant difference while adhesive mode of failure was the predominant in group IIa (60\%) with significant difference $(p=0.008)$. (Table II) (Fig. 2)

\section{Microleakage}

There was statistically significant difference in microleakage score between the two groups. Group Ib (VF) showed significant lower microleakage scores with $\mathrm{p}$ value equals 0.000 (Z=4.845). (Table III) (Fig. 3)

Table 1: Comparison of shear bond strength (MPa) between the two studied groups

\begin{tabular}{|l|c|c|}
\hline \multicolumn{1}{|c|}{$\begin{array}{c}\text { Shear Bond } \\
\text { Strength }\end{array}$} & Group Ia & Group IIa \\
\hline Min- Max & $9.390-15.900$ & $4.110-7.520$ \\
\hline Mean \pm SD & $12.584 \pm 1.998$ & $5.800 \pm 1.107$ \\
\hline Inter-quartile range & $11.270-14.160$ & $5.070-6.970$ \\
\hline Median & 12.490 & 5.660 \\
\hline KS test & $\begin{array}{c}\mathrm{D}=0.121 \\
\mathrm{p}=0.200 \mathrm{NS}\end{array}$ & $\begin{array}{c}\mathrm{D}=0.151 \\
\mathrm{p}=0.200 \mathrm{NS}\end{array}$ \\
\hline $\begin{array}{l}\text { Mann-Whitney U } \\
\text { test }\end{array}$ & \multicolumn{2}{|c|}{$\mathrm{p}=0.660$} \\
\hline $\begin{array}{l}\text { KS: Kolmogorov-Smirnov test of normality } \\
\text { * Statistically significant at } \mathrm{P} \leq 0.05\end{array}$
\end{tabular}

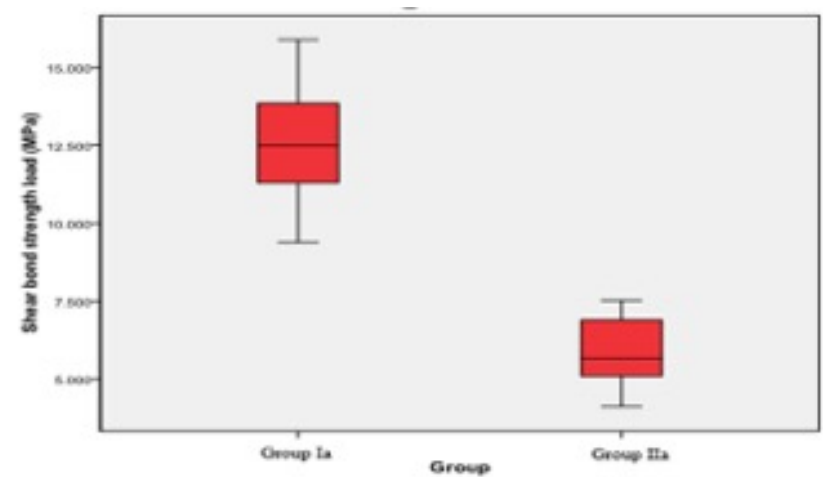

Figure 1: Box and whisker graph of shear bond strength (MPa) in the two studied groups.

Table (2): Comparison of mode of failure between the two studied groups.

\begin{tabular}{|c|c|c|}
\hline $\begin{array}{c}\text { Mode of } \\
\text { failure }\end{array}$ & $\begin{array}{c}\text { Group Ia } \\
(n=15)\end{array}$ & $\begin{array}{c}\text { Group IIa } \\
(n=15)\end{array}$ \\
\hline Adhesive & $2(13.3 \%) \mathbf{0 . 0 0 8 0}$ * & $\begin{array}{c}9 \\
(60.0 \%) \mathbf{0 . 0 0 8 0 *}\end{array}$ \\
\hline Cohesive & $3(20.0 \%)$ & $1(6.7 \%)$ \\
\hline Mixed & $10(66.7 \%)$ & $5(33.3 \%)$ \\
\hline & \multicolumn{2}{|c|}{$\begin{array}{l}\mathrm{X}^{2}(\mathrm{df}=2)=7.121 \\
\mathbf{p}_{(\mathrm{MC})}=\mathbf{0 . 0 3 2} *\end{array}$} \\
\hline
\end{tabular}

\section{$\mathrm{X}^{2:}$ Pearson Chi-Square}

MC: Monte Carlo correction

* Statistically significant at $\mathrm{P} \leq 0.05$

Bonferroni Adjusted p value for post-hoc $=0.0083$ (0.05/6)
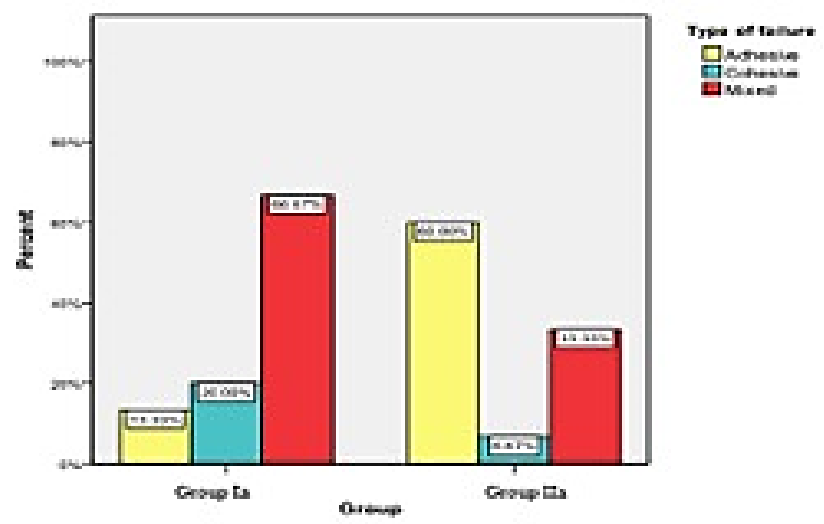

Figure 2: Bar graph representing the mode of failure in the two studied groups.

Table 3: Comparison between the two studied groups according to Microleakage score.

\begin{tabular}{|c|c|c|c|c|}
\hline & \multicolumn{2}{|c|}{$\begin{array}{c}\text { Group Ib } \\
\text { (vertise flow) } \\
(n=15)\end{array}$} & \multicolumn{2}{|c|}{$\begin{array}{c}\text { Group IIb } \\
\text { (Clinpro } \\
\text { sealant+PLP) } \\
(n=15)\end{array}$} \\
\hline & No. & $\%$ & No. & $\%$ \\
\hline $\begin{array}{c}\text { Microleakage score } \\
0 \\
1 \\
2 \\
3\end{array}$ & $\begin{array}{l}9 \\
5 \\
1 \\
0\end{array}$ & $\begin{array}{c}60.0 \\
33.3 \\
6.7 \\
0.0\end{array}$ & $\begin{array}{c}0 \\
0 \\
4 \\
11\end{array}$ & $\begin{array}{r}0.0 \\
0.0 \\
26.7 \\
73.3\end{array}$ \\
\hline Min- Max & \multicolumn{2}{|c|}{$0.0-2.0$} & \multicolumn{2}{|c|}{$2.0-3.0$} \\
\hline Mean \pm SD. & \multicolumn{2}{|c|}{$0.4667 \pm 0.639$} & \multicolumn{2}{|c|}{$2.80 \pm 0.414$} \\
\hline Median & \multicolumn{2}{|c|}{0.0} & \multicolumn{2}{|c|}{3.0} \\
\hline Inter-quartile range & \multicolumn{2}{|c|}{$0.00-1.00$} & \multicolumn{2}{|c|}{$3.00-3.00$} \\
\hline $\mathrm{Z}(\mathbf{p})$ & \multicolumn{4}{|c|}{$4.845 *(0.000 *)$} \\
\hline
\end{tabular}

Z: Mann-Whitney U test*: statistically significant at $\mathrm{p} \leq 0.05$. 


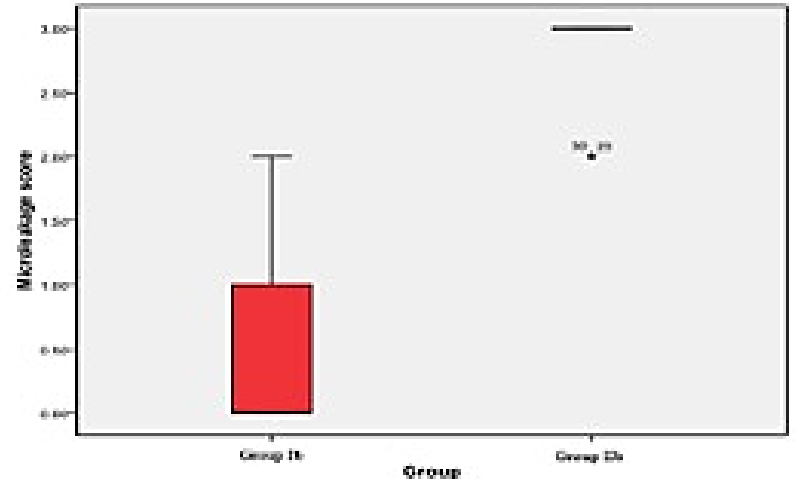

Figure 3: Box and whisker graph of microleakage score in the two studied groups.

\section{DISCUSSION}

The objective of this study was to evaluate retention and sealing ability of a self-adhering flowable composite Vertise Flow VF (Group I) when used in pit and fissure sealing in term of microleakage and shear bond strength in vitro and in comparison to a conventional pit and fissure sealant (Clinpro sealant) used with a SEA (Group II).

In order to achieve proper adhesion of VF, the manufacturer and laboratory studies recommend that the enamel substrate should be pre-etched with phosphoric acid $(19,24-27)$. This may be due to the presence of prismless enamel in pits and fissures. Conversely, Ernst (28) and Erhardt et al (29) had reported that pre-treatment with phosphoric acid had little effect and does not improve enamel bonding effectiveness with most SEA. Accordingly, acid pre-etching was done in group I only following both manufacturers' recommendations and literature.

Bond strength is thought to be predictive of materials' retentive ability. For sealants, it is considered to be a very reliable parameter in the quantification of their adhesive ability on enamel substrate. Shear bond strength testing of sealants is based on the premise that the stronger the toothsealant adhesion or bond (higher bond strength) the better it will resist curing stresses and oral loading (functional stresses) (30).

In the present study, the mean shear bond strength of VF was significantly higher than that of Clinpro sealant and PLP. The higher bond strength of VF in comparison with Clinpro sealant and PLP can be ascribed to many factors. The actual composition and the functional monomer contained in VF (GPDM) is probably the most important factor where it has proven good adhesive performance in both laboratory and clinical research (26). The difference in the adhesion/polymerization process can be also considered. When the adhesive solution and the resin-based sealant are applied consecutively, as in case of Clinpro Sealant, curing stress of the sealant competes against the bond just established by the adhesive (16). Conversely, with VF bonding and polymerization take place simultaneously. It can therefore be speculated that the competition between bond strength and curing stress is reduced as the viscous-elastic flow occurs concurrently with the bonding process (12). This finding was supported by Juloski et al (19). On the contrary, Margvelashvili et al (12) found that there was no significant difference between self-adherable flowable composite, conventional sealant used with SEA and sealant used with acid etchant regarding bond strength. This contradiction may be attributed to the smaller sample size involved in Margvelashvili's study.

Regarding the mode of failure, VF showed significantly lower adhesive failure than Clinpro sealant and PLP group. The lower tendency towards adhesive failure of the VF may thus be attributed to its higher bond strength together with the effect of PA over the enamel surface during conditioning (31).

Microleakage analysis using dyes was shown to be indicative of the sealing ability and predictive of bacteria percolation as the size of tracer molecules conforms to that of bacteria. Dye leakage method is simple, inexpensive and does not require the use of complex laboratory equipment. Moreover, being organic, avoids its chemical reaction and destruction to specimens (32). In order to simulate changing intraoral temperature conditions and create the aging effects that restorative materials are subjected to in the oral cavity, all teeth were subjected to thermocycling between $5^{\circ} \mathrm{C}$ and $55^{\circ} \mathrm{C}$ for 500 cycles which is considered to be an appropriate test for aging dental materials $(33,34)$.

Regarding the microleakage analysis, group Ib showed statistically significant lower microleakage score. Microleakage occurred only in $40 \%$ of all VF specimens, where dye penetration was restricted to the outer half of the fissures. As for Clinpro sealant group, $100 \%$ of the specimens showed dye penetration ranging from inner half to full depth of the fissures. As a possible explanation for the lower microleakage score, it has been reported that VF undergoes hygroscopic expansion. This might have contributed to improve marginal adaptation by compensating resin polymerization shrinkage (35). Margvelashvili et al (12) and Derelioglu et al (30) reported VF to have comparable microleakage to conventional composite resin pit and fissure sealant while Elmotayam et al (36) reported lower incidence of nanoleakage in VF. On the other hand, Gonulol et al (25) reported higher microleakage to enamel in VF than two other flowable composites. This contradiction in results may be attributed to different techniques used to evaluate microleakage and different materials employed in these studies.

The overall results of the present study indicated that Vertise Flow (VF) showed better retention and lower microleakage than Clinpro sealant used with SEA when used as pit and fissure sealant. The results of the current study thus necessitate the rejection of the null hypothesis that VF and Clinpro sealant used in combination with PLP achieve similar shear bond strength to enamel and comparable seal to pit and fissure walls.

Although the study methodology attempted to stimulate the oral condition as closely as possible, extracted teeth lack the pulp pressure and intertubular fluid pressure present in the natural teeth in the oral cavity, which has influence on teeth moisture level affecting both microleakage and restoration-tooth interface (26). In addition, in vitro studies can exaggerate bonding capabilities due to a well-controlled environment that could not be possible in the clinical situation. Within the limitation of this study, VF had shown encouraging results in vitro to be used as fissure sealant. However, it does not hold the added benefit of time saving and procedure facilitation, since when applied to enamel, acid etching was still mandatory. Further studies of other physical properties and clinical studies are needed. The use of VF in PRR and in primary teeth need to be also studied. 


\section{CONCLUSIONS}

Within the limitations of the present study it may be concluded that VF have significantly higher retention and better sealing ability to pits and fissures when compared to Clinpro sealant used with PLP.

\section{CONFLICT OF INTEREST}

The authors declare that they have no conflict of interest.

\section{REFERENCES}

1. Simonsen RJ. Pit and fissure sealant: review of the literature. Pediatr Dent. 2002; 24: 393-414.

2. Tyas MJ, Anusavice KJ, Frencken JE, Mount GJ. Minimal intervention dentistry--a review. FDI Commission Project 1-97. Int Dent J. 2000; 50: 1-12.

3. Simonsen RJ. Chapter 2: Pit and fissure sealants. In: Clinical Applications of the Acid Etch Technique. 1st ed. Chicago, IL: Quintessence Publishing Co, Inc; 1978:19-42.

4. Siegal MD. Workshop on guidelines for sealant use. J Publ Health Dent. 1995; 55: 259-311.

5. Coronal SAM, Borsatto MC, Garcia L, Ramos RP, PalmaDibb RG. Randomized controlled trial comparing the retention of a flowable restorative system with a conventional resin sealant: one year follow up. Int J Paediatr Dent. 2005; 15: 44-50.

6. Pérez LL, Cortés LO, García BC, Cózar HA. Marginal microleakage of the fissure sealants: a comparative study. J Dent Child. 2003; 70: 24-8.

7. Feigal RJ, Quelhas I. Clinical trial of a self-etching adhesive for sealant application: success at 24 months with Prompt L-Pop. Am J Dent. 2003; 16: 249-51.

8. Beauchamp J, Caufield W, James J, Caufield PW, Crall JJ, Donly K, et al. Evidence-based clinical recommendations for the use of pit-and-fissure sealants a report of the American Dental Association Council on scientific affairs. JADA. 2008; 139: 257-68.

9. Tavassoli SH, Mehran M, Noori ET, Hedeshi RM. Effect of Self-Etching and Single-Bottle Bonding Systems on Shear Bond Strength of Fissure sealant to Primary and Permanent Enamel. JIDAI. 2014; 26: 6-12.

10. Mascarenhas AK., Nazar H., Al-Mutawaa S, Soparkar P. Effectiveness of primer and bond in sealant retention and caries prevention. Pediatr Dent. 2008; 30: 25-8.

11. Papacchini F, Goracci C, Sadek FT, Monticelli F, Garcia GF, Ferrari M. Microtensile bond strength to ground enamel by glass-ionomers, resin-modified glass-ionomers, and resin composites used as pit and fissure sealants. J Dent. 2005; 33: 459-67.

12. Margvelashvili M, Vichi A, Carrabba M, Goracci C, Ferrari M. Bond Strength to Unground Enamel and Sealing Ability in Pits and Fissures of a New Self-Adhering Flowable Resin Composite. J Clin Pediatr Dent. 2013; 37: 397-402.

13. Vichi A, Margvelashvili M, Goracci C, Papacchini F, Ferrari M. Clinical study of the self-adhering flowable composite resin Vertise Flow in Class I restorations: sixmonth follow-up. Int Dent SA. 2010; 12: 14-23.

14. Czasch P, Ilie N. In vitro comparison of mechanical properties and degree of cure of a self-adhesive and four novel flowable composites: J Adhes Dent. 2013; 15: 22936.

15. Alsaleh MM. Clinical and laboratory evaluation of flowable composite as pit and fissure sealing material used on permanent molars. MD thesis. Alexandria University Egypt. 2009.
16. Moszner N, Salz U, Zimmermann J. Chemical aspects of self-etching enamel-dentin adhesives: a systematic review. Dent Mater. 2005; 21: 895-910.

17. Eliades A, Birpou E, Eliades T, Eliades G. Self-adhesive restorations as pit and fissure sealants: A comparative laboratory study. Dent Mater. 2013; 29:752-62.

18. Sharaf A. The use of a self-etching adhesive in the application of pit and fissure sealant: an in vivo and in vitro study. Egy Dent J. 2003; 49: 1319-26.

19. Juloski J, Goracci C, Rengo C, Giovannetti A, Vichi A, Vulicevic ZR, et al. Enamel and dentin bond strength of new simplified adhesive materials with and without preliminary phosphoric acid-etching. Am J Dent. 2012; 25: 239-43.

20. Pardi V, Sinhoreti MA, Pereira AC, Ambrosano GM, Meneghim Mde C. In Vitro Evaluation of Microleakage of Different Materials Used as Pit and Fissure Sealants. Braz Dent J. 2006; 17: 49-52.

21. Yavuz I, Aydin AH, Ulku R, Dulgergil TC, Akdag MZ. New technique: Measurement of microleakage volume in the marginal gaps of the dental restorations. Biotechnol Biotech Equip. 2005; 19: 184-91.

22. Ovrebo RC, Raadal M. Microleakage in fissures sealed with resin or glass ionomer cement. Scand J Dent Res. 1990; 98 : 66-9.

23. IBM SPSS Statistics for Windows, Version 21.0. Armonk, NY: IBM; 2012.

24. Garcia N, Morelli E, Silva D, Giongo M, Pollheim P, Largura $\mathrm{S}$, et al. Bonding performance of a self-adhering flowable composite to substrates used in direct technique. RSBO. 2013; 10: 143-9.

25. Gonulol N, Ertas E, Yilmaz A, Cankaya S. Effect of thermal aging on microleakage of current flowable composite resins. JDS. 2014; 3: 1-7.

26. Pipatphatsakorn M. Microtensile bond strength of new selfadhesive flowable resin composite, Vertise ${ }^{\circledR}$ Flow $^{\mathrm{TM}}$, on Different Enamel Substrates. CU Dent J. 2015; 38: 83-96.

27. Technical Bulletin/Vertise Flow Self Adhering Flowable Composite.Orange, CA, USA: Kerr Sybron Dental Specialties, 2010.

28. Ernst CP. Positioning self-etching adhesives: versus or in addition to phosphoric acid etching. J Esthet Restor Dent. 2004; 16: 57-69.

29. Erhardt MC, Cavalcante L, Assad M, Pimenta LA. Influence of Phosphoric Acid Pretreatment on Self-Etching Bond Strengths. J Esthet Restor Dent. 2004; 16: 33-40.

30. De Munck J, Van Landuyt K, Peumans M, Poitevin A, Lambrechts P, Braem $\mathrm{M}$, et al. A critical review of the durability of adhesion to tooth tissue: methods and results. J Dent Res. 2005; 84: 118-32.

31. Derelioglu SS, Yilmaz Y, Celik P, Carikcioglu B, Keles S. Bond strength and microleakage of self-adhesive and conventional fissure sealants. Dent Mater J. 2014; 33: 5308.

32. Raskin A, Tassery H, D’hoore W, Gonthier S, Vreven J, Degrange $\mathrm{M}$, et al. Influence of the number of specimens on the reliability of in vitro microleakage evaluations. Am J Dent. 2003; 6: 207-10.

33. International Organization for Standardization. Dental Materials-Testing of adhesion to tooth structure. ISO/TS 11405; 2015.

34. Wei J, Silikas N, Zhang ZT, Watts C. Hygroscopic dimensional changes of self-adhering and new resin-matrix composites during water sorption/desorption cycles. Dent Mater. 2011; 27: 259-66. 
35. Guelmann M, Bonnini S, Primosch RE, Soderholm KJ. Microleakage and wall adaptation of conservative restorations. Am J Dent. 2002; 15: 407-11.

36. ElMotyam K, Walid A, Youssef R. Assessment and comparison of nanoleakage and resin tag length of three different pit and fissure sealants: An In-vitro scanning electron microscope study. J Am Sci. 2013; 9: 329-37.

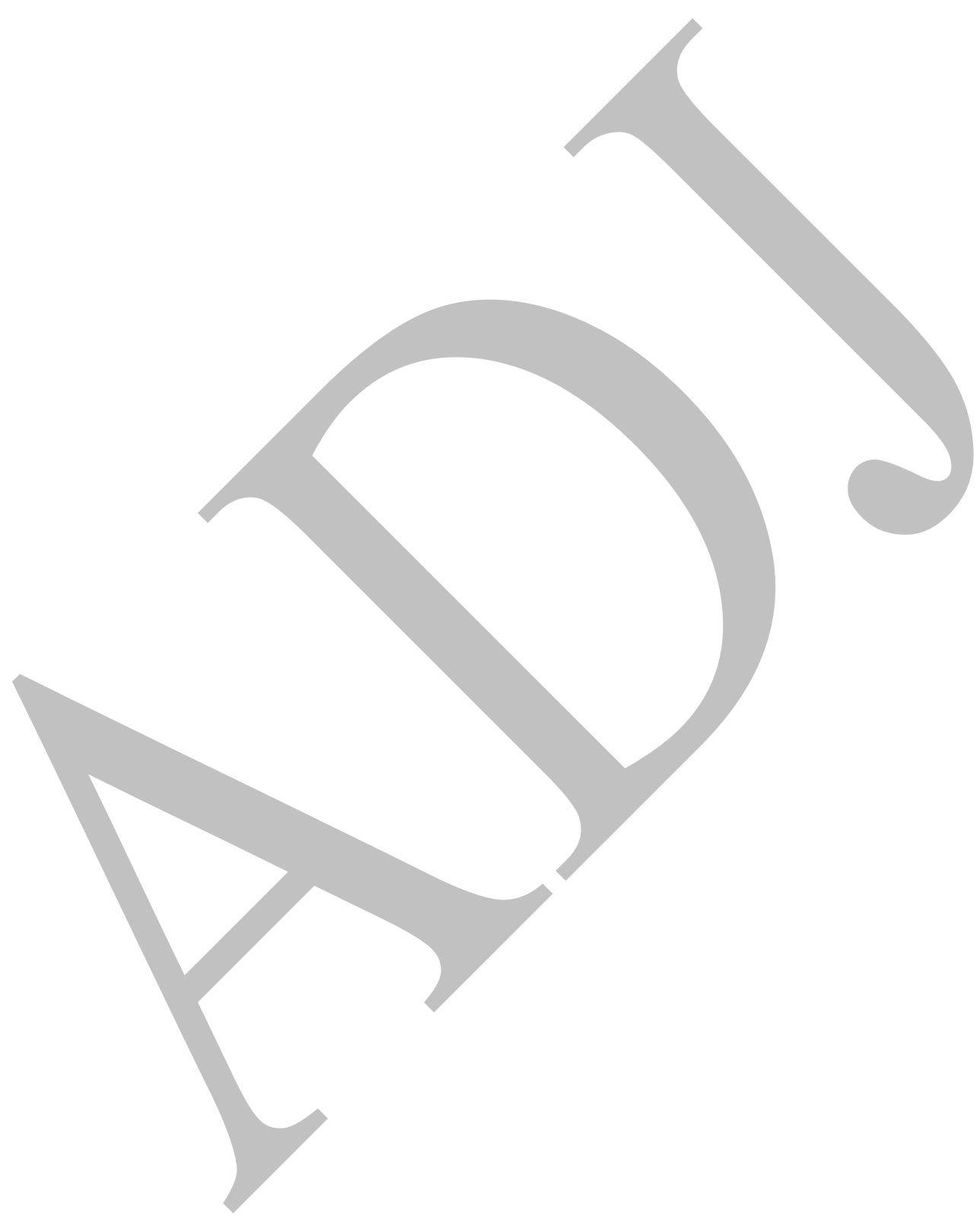

